\title{
MOSTRA DE CIÊNCIAS COMO UMA FORMA DE APRENDIZAGEM A PARTIR DA EXPERIMENTAÇÃO
}

\author{
SCIENCE EXHIBITION AS A WAY OF LEARNING FROM \\ EXPERIMENTATION
}

\author{
Cristiano Rodeski Pires (cristiano.rks@hotmail.com) \\ Colégio Estadual João de Castilho - Salvador das Missões -RS
}

\begin{abstract}
Resumo: Este relato é resultado da realização da I Mostra de Ciências do Município de Salvador das Missões - RS. Tal mostra ocorreu no ano de 2017 em parceria com a rede municipal e estadual de ensino envolvendo os alunos do Ensino Fundamental e Médio. Um dos pré-requisitos para inscrição na mostra era apresentar um experimento relacionado com os conteúdos vistos durante o ano letivo de 2016 a 2017 na área de Ciências da Natureza. Obtivemos no total 20 experimentos inscritos. Também foi confeccionado pelos alunos um relatório, com todos os passos do experimento, expectativas, dificuldades e aprendizados. Como resultados indicamos que esse tipo de atividade desperta o interesse do aluno e proporciona momentos de reconhecer que o erro também faz parte da construção da Ciência. Dessa forma o ensinar e aprender se tornam significativos e possibilitam melhorar o entendimento dos fenômenos da área de Ciências da Natureza.
\end{abstract}

Palavras-chave: Ensino de Ciências; Aprendizagem; Prática Científica.

Abstract: This report is the result of the 1st Science Exhibition from the City of Salvador das Missões - RS. This show took place in 2017 in partnership with the municipal and state school system involving elementary and high school students. One of the prerequisites for registration in the exhibition was to present an experiment related to the content seen during the 2016-2017 school year in the area of Natural Sciences. We obtained a total of 20 submitted experiments. A report was also made by the students, with all the steps of the experiment, expectations, difficulties and learning. As results we indicate that this type of activity arouses the student interest and provides moments to recognize that the error is also part of the construction of Science. In this way teaching and learning become significant and make it possible to improve understanding of the phenomena of the area of natural sciences.

Keywords: Science Teaching; Learning; Scientific Practice. 


\section{Vol. 2, n. 3 - Edição Especial: Ciclos Formativos em Ensino de Ciências.}

\section{INTRODUÇÃO}

A experimentação é de extrema importância para o ensino de Ciências, pois possibilita aos alunos o interesse pelo conhecimento científico. No ensino de Ciências da Natureza que abrange Biologia, Física e Química podemos destacar as dificuldades dos alunos para associar as teorias com as vivências de seu cotidiano. Segundo Freire (1997) é preciso compreender a teoria para poder relacioná-la e, é nesse sentido que apontamos a experimentação como uma ferramenta que auxilia no processo de aprender.

As feiras de Ciências ou Mostras vêm sendo utilizadas desde a década de 60, como ferramentas de ensino e aprendizagem. As primeiras Feiras caracterizavam-se por apresentar trabalhos resultantes de experiências feitas em aula ou montagem de aparelhos utilizados com fins demonstrativos (MANCUSO,1995).

As Mostras de Ciências são conhecidas como atividades pedagógicas e culturais com elevado potencial motivador de ensino e da prática científica no ambiente escolar, de modo especial, na área de Ciências da Natureza. Na maioria das atividades, a melhor maneira de aprender é fazendo, desse modo uma das etapas de maior importância do método científico é a experimentação, que consiste na escolha da temática, no estudo teórico, na elaboração e construção de prática e na compreensão de todo o fenômeno. Tal movimento possibilita aos alunos desenvolver o raciocínio lógico e coerente, facilitando a construção e a compreensão acerca dos fatos científicos e até mesmo a resolução de problemas práticos.

Diante dessas potencialidades foi desenvolvido um projeto que visou a organização da I Mostra de Ciências do município de Salvador das Missões, com o envolvimento de todos os alunos das Séries Finais do Ensino Fundamental e Ensino Médio da rede estadual e municipal. Os trabalhos foram orientados pelos professores da área de Ciências da Natureza de cada uma das instituições de ensino.

A mostra é uma maneira de socializar as produções, dando visibilidade aos experimentos, bem como contribuir com a difusão do conhecimento entre a comunidade 


\section{Vol. 2, n. 3 - Edição Especial: Ciclos Formativos em Ensino de Ciências.}

escolar. Segundo Pereira (2000), as Mostras ou Feiras de Ciências têm como objetivos propiciar um conjunto de situações de experiências que possibilitem:

[...] incentivar a atividade científica; favorecimento da realização de ações interdisciplinares; estimular o planejamento e execução de projetos; estimular o aluno na busca e elaboração de conclusões a partir de resultados obtidos por experimentação; desenvolver a capacidade do aluno na elaboração de critérios para compreensão de fenômenos ou fatos, pertinentes a qualquer tipo, quer cotidiano, empírico ou científico; proporcionar aos alunos expositores uma experiência significativa no campo sócio-científico de difusão de conhecimentos; integração da escola com a comunidade, (PEREIRA, 2000, p.20).

De acordo com essas propostas, os estudantes ao conhecerem os métodos científicos, e se apropriarem dos conceitos vistos nos experimentos são estimulados a compreender melhor a Ciência e a sua força transformadora do mundo.

Pois a educação em Ciências nos dias atuais não pode se ater somente na simples teorização formal em sala de aula. Desse modo os espaços de formação científica, aparecem cada vez mais em meios informais, com aulas contextualizadas e utilização de experimentação, e a partir dessas concepções aqui expressas apontamos para a importância de investigar a formação conceitual e científica decorrente da I Mostra de Ciências realizada em Salvador das Missões.

\section{DESCRIÇÃO DAS ATIVIDADES}

A I Mostra de Ciências desenvolveu-se com os alunos das séries finais do Ensino Fundamental e Ensino Médio do Colégio Estadual João de Castilho pertencente a $14^{a}$ Coordenadoria de Educação do Estado do Rio Grande do Sul e alunos da Escola Municipal de Ensino Fundamental Afonso Rodrigues, do município de Salvador das Missões - RS, tendo como objetivo, despertar o interesse pela investigação científica dos alunos.

Entre os meses de março e maio ocorreu o planejamento das ações a serem realizadas. Dentre essas destacam-se a construção das regras para escolha de um desenho, que representasse o evento. Após iniciou-se a escolha dos experimentos que os alunos iriam realizar na I Mostra de Ciências. Cada grupo era composto por, no 


\section{Vol. 2, n. 3 - Edição Especial: Ciclos Formativos em Ensino de Ciências.}

máximo, cinco alunos. Além dos experimentos os alunos realizaram a elaboração de relatórios. As temáticas dos trabalhos inscritos emergiram de conteúdos vistos no ano de 2016 e 2017 na área de Ciências da Natureza, perfazendo um total de 20 experimentos.

Após a escolha do experimento e testes iniciais, os grupos confeccionaram um relatório com introdução, objetivo, materiais, metodologia, resultados, conclusão e referencial bibliográfico. Após a confecção dos relatórios os mesmos foram enviados aos professores da área de Ciências da Natureza para correção. Todos os trabalhos foram selecionados para a mostra.

A I Mostra de Ciências ocorreu no dia 24 de outubro de 2017 (terça-feira) no ginásio do Colégio Estadual João de Castilho. Nesse dia a escola funcionou em um único turno (manhã), em que a comunidade externa e alunos das séries iniciais da rede estadual e municipal fizeram suas visitas aos experimentos apresentados. A avaliação esteve presente em três momentos: I) escolha do experimento, montagem e coerência com os conteúdos da área de Ciências da Natureza; II) elaboração do relatório do experimento; III) apresentação do experimento para seis jurados sem vínculo com as escolas.

Os resultados que apresentamos foram construídos mediante a análise dos relatórios dos estudantes, e cada um dos excertos retirados dos relatórios serão identificados como (G1, G2..). Assim, caracterizamos a análise de cunho qualitativo e investigativo sobre as concepções de experimentação, relevância da experimentação para o ensino de Ciências e investigação científica que foram possíveis de serem identificados nas escritas dos relatórios confeccionados pelos alunos.

\section{DISCUSSÃO DA PRÁTICA}

As Feiras ou Mostras de Ciências, são instrumentos educativos que vêm sendo utilizados a quase sessenta anos no Brasil, pois possibilitam o protagonismo dos alunos em sua aprendizagem pois os mesmos são responsáveis pela apresentação, planejamento e execução dos experimentos. Segundo Lima (2011) as Feiras ou Mostras de Ciências estimulam a colaboração entre o grupo uma vez que, 


\section{Vol. 2, n. 3 - Edição Especial: Ciclos Formativos em Ensino de Ciências.}

na realização de um trabalho, a dimensão e as demandas do trabalho leituras, pesquisas, entrevistas, realização de experiências, construções, sistematização e roteiros de apresentação - envolvem um esforço que requer planejamento, divisão de tarefas, colaboração na equipe de trabalho e controle das ações (LIMA, 2011, p. 196).

$\mathrm{O}$ trabalho em equipe demonstra o comprometimento, responsabilidade por todos os alunos envolvidos em que cada um quer dar o seu melhor, pois a apresentação é para a comunidade externa e não somente para os colegas.

Importante ressaltar que a experimentação de forma isolada não consegue uma relação entre o conhecimento científico, mas com a junção da teoria e manuseio o aluno consegue superar os desafios da construção de conhecimentos. $\mathrm{O}$ aluno consegue se defrontar com qualquer tema pertinente com noção da teoria e prática e desfazer ideias intuitivas. Nesse sentido Demo (2002) ressalta:

a capacidade de se confrontar com qualquer tema é uma construção: Condensa-se na habilidade de sabendo reconstruir conhecimento, enfrentar qualquer desafio de conhecimento, porque sabe pensar, aprende a aprender, maneja criativamente lógica, raciocínio, argumentação, dedução e indução, teoria e prática (DEMO, 2002, p.90).

A utilização da experimentação no ensino de Ciências da Natureza é uma via de mão de mão-dupla entre a teoria e a prática, pois o aluno passa a argumentar, investigar, reconduzindo a sua apropriação de conceitos. Nesse sentido Fagundes (2007) descreve que:

a atividade prática favorece a compreensão das Ciências Naturais. Neste caso, fica clara a interdependência entre teoria e atividades experimentais, ou seja, em Ciências não existe teoria desvinculada da prática, nem prática sem seus pressupostos teóricos. Nesse viés, é importante proporcionar espaços para relatos (diálogo), discussões e reflexões (FAGUNDES, 2007,p. 323)

A Ciência nesse contexto se torna um instrumento de discussões e reflexões no meio social e científico e a I Mostra de Ciências possibilitou a comunidade esse espaço de diálogo e interação através dos experimento realizados pelos alunos. Podemos ressaltar esse processo de escrita no relatório do (G 1): A Amostra de Ciências nos leva a um mundo de importantes demonstrações, as quais muitas vezes, aparentam ser incompreensíveis, ou até mesmo surreais. Também é um local para se apresentar algo que possa vir a ser utilizado em ocasiões posteriores, seja em casa, escola, trabalho ou 


\section{Vol. 2, n. 3 - Edição Especial: Ciclos Formativos em Ensino de Ciências.}

sociedade em geral. O grupo enfatiza que o conhecimento estará presente em diversos momentos e não somente na escola.

Os alunos se mostraram criativos, pois muitos grupos utilizaram materiais alternativos, para a realização de seus experimentos. As observações realizadas por parte de alguns grupos, os quais o experimento deu errado, fica bem claro que a experimentação é levada pela curiosidade e construção do conhecimento, o (G2) ressalta: sempre quis entender como ocorre os furações por isso propus ao meu grupo realizarmos o experimento do furação em um copo. Nos primeiros testes não conseguimos que nosso experimento desse certo, então após o auxílio do professor e uma pesquisa, percebemos que deveríamos utilizar um Hd interno com um interruptor.

O experimento que faz o movimento de reflexão e desmistificação da Ciência para o aluno propõem que o erro faz parte para a construção do conhecimento e assim possibilita uma outra compreensão acerca da construção da Ciência.

\section{CONCLUSÃO}

A experimentação tem um papel fundamental na área de Ciências da Natureza, uma vez que aproxima o aluno em seu processo de ensino-aprendizagem. Nesse processo a I Mostra de Ciências vem fomentar a investigação o que contribui para a qualidade no ensino de Ciências. Pois as mesmas motivam os alunos a buscarem respostas aos fenômenos de seu cotidiano e melhorar o meio em que vivem.

A I Mostra de Ciências desafiou os alunos a iniciação à prática da pesquisa, possibilitou a discussão de alguma temática, exigiu um trabalho em equipe e reflexivo, além de instigar a criatividade na adaptação dos materiais para que os experimentos ocorressem de maneira adequada. Também a busca de explicações científicas do por que determinados experimentos não saíram como o planejado, situações que demonstraram aos alunos que a Ciência não é estática, mas que está em constante transformação.

Acreditamos que as Mostras de Ciências, possibilitam mediações dos conhecimentos científicos entre os alunos. Além de ser um agente de transformação e 
Revista Insignare Scientia

Vol. 2, n. 3 - Edição Especial: Ciclos Formativos em Ensino de Ciências.

aproximação do conhecimento com a comunidade escolar e o meio social onde esses alunos estão inseridos.

\section{REFERÊNCIAS}

DEMO, Pedro. Educar pela pesquisa. São Paulo: Autores Associados, 2002.

FAGUNDES, S. M. K. Experimentação nas Aulas de Ciências: Um Meio para a Formação da Autonomia? 2007. p, 323.

FREIRE, P. Pedagogia da Autonomia. Rio de Janeiro: Paz e Terra, 1997.

LIMA, Maria Edite Costa. Feiras de ciências: o prazer de produzir e comunicar. In: PAVÃO, Antonio Carlos; FREITAS, Denise de (Org.). Quanta ciência há no Ensino de Ciências? São Carlos: Edufscar, 2011. Cap. 4. p. 195-205.

PEREIRA, A. B.; OAIGEN, E.R.; HENNIG.G. Feiras de Ciências. Canoas: Ulbra,2000.

MANCUSO, R. Programa estadual de Feiras de Ciências do Rio Grande do Sul. Porto Alegre: SEC/CECIRS,1995.

SILVA, L. H. A; ZANON, L. B. Experimentação no ensino de ciências. In: SCHNETZER, Roseli P.; ARAGÃO, R. M. R. (Orgs.) Ensino de Ciências: fundamentos e abordagens. Campinas: V Gráfica, 2000. p. 120-153. 